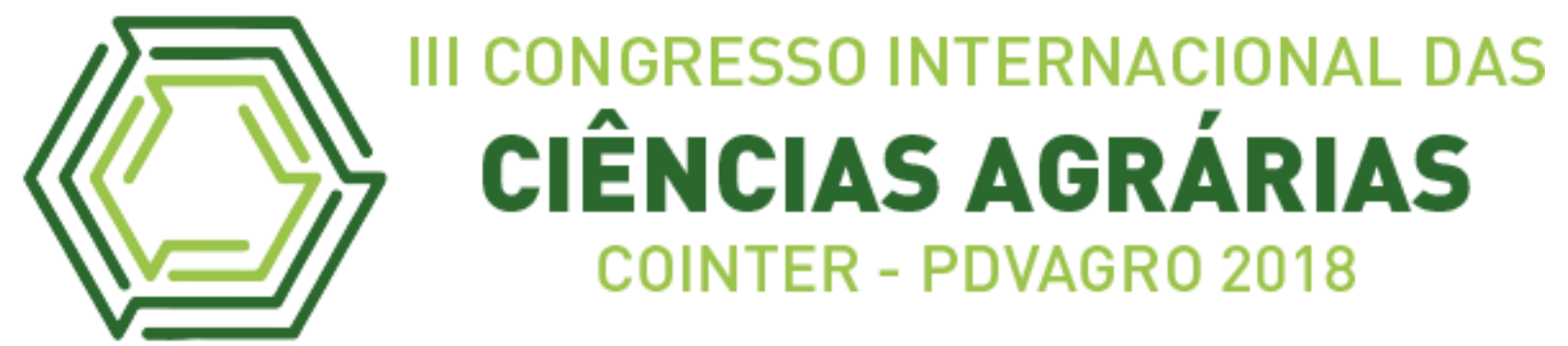

\title{
CARACTERIZAÇÃo DA ARBORIZAÇÃO URBANA DA REGIÃO CENTRAL DO MUNICÍPIO DE SANTARÉM-PA
}

\section{CHARACTERIZATION OF URBAN AFFORESTATION ON THE CENTRAL REGION OF THE CITY SANTARÉM-PA}

\author{
Apresentação: Pôster

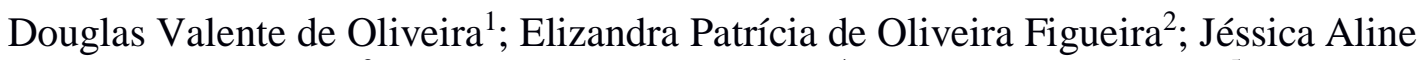 \\ Godinho da Silva ${ }^{3}$; Vânia Lúcia Xavier Viana ${ }^{4}$; Mayra Piloni Maestri ${ }^{5}$
}

\section{DOI: https://doi.org/10.31692/2526-7701.IIICOINTERPDVAGRO.2018.00357}

\section{Introdução}

O Brasil é considerado um país urbano, atualmente, como demonstra uma pesquisa do Instituto Brasileiro de Geografia e Estatística - IBGE, a qual enfatiza que 84,36\% da população reside nas cidades, cenário diferente da década de 1970, na qual esse número não ultrapassava os 30\% (IBGE, 2010). Entretanto, essa expansão urbana desordenada vem causando desiquilíbrios ambientais, no que tange a arborização urbana, uma vez que, são grandes as dificuldades de se implantar o verde nas cidades, principalmente conciliado à presença de equipamentos urbanísticos, como instalações hidráulicas e redes elétricas, telefônicas ou sanitárias.

A arborização urbana possui grande importância na qualidade de vida das pessoas, com influência direta sobre a amenização do clima, por conta da sombra proporcionada e a evapotranspiração necessárias à regulação de temperatura e umidade na melhoria das condições microclimáticas, retém a água da chuva por tempo suficiente para permitir um escoamento gradual, benefícios paisagísticos, melhoria da qualidade do ar, alimento e refúgio para a fauna e, com isso, propiciando um ambiente equilibrado e salvaguardando a identidade biológica regional (PAULA, 2015).

\footnotetext{
${ }^{1}$ Engenharia Florestal, Universidade Federal do Oeste do Pará, douglasvalenteoliveira@hotmail.com

${ }^{2}$ Engenharia Florestal, Universidade Federal do Oeste do Pará, elizandrafigueira@hotmail.com

${ }^{3}$ Engenharia Florestal, Universidade Federal do Oeste do Pará, alinnygiordan@gmail.com

${ }^{4}$ Engenharia Florestal, Universidade Federal do Oeste do Pará, niahviana@gmail.com

${ }^{5}$ Mestre em Ciências Florestais, Universidade Federal do Oeste do Pará, mayrapmaestri@hotmail.com
} 
Diante desse cenário, torna-se necessária a implantação de árvores nas cidades. Porém esta implantação deve ser realizada de forma planejada e organizada para evitar futuros problemas com espécies inadequadas para o meio urbano, tais como degradação de patrimônio público, residências e conflitos com os elementos urbanísticos existentes e necessários a vida em sociedade nos centros urbanos (LOPO, 2014).

Com isso, o presente estudo teve como objetivo caracterizar o estado atual da arborização urbana no bairro centro da cidade de Santarém, Pará.

\section{Fundamentação Teórica}

De acordo com Biondi e Lima Neto (2014), realizar um inventário das árvores presentes no meio urbano é o meio que proporciona uma economia de gastos com tratos silviculturais e manutenção e fornece informações sobre as prioridades de intervenções, tais como os tratamentos fitossanitários, remoção de árvores, plantios e/ou replantios e necessidade de podas.

Conforme Biondi (2015) a arborização de ruas é o "plantio linear de vegetação arbórea em ambientes com alto grau de antropização, principalmente com a presença de calçadas, asfalto, construções e população urbana".

Para realizar o planejamento do projeto de arborização deve-se considerar as atividades relacionadas ao levantamento das condições atuais dos indivíduos, condições físico-sanitárias, informações de manejo, identificação dos indivíduos com ausência de poda e incentivo ao uso de espécies nativas (GONÇALVES, 2018). Além disso, deve estar presente no projeto de arborização um plano de monitoramento e de manutenção pós-plantio.

\section{Metodologia}

O município de Santarém está situado na região Oeste do estado do Pará, extensão geográfica de $17.898 \mathrm{Km}^{2}$ e, aproximadamente, 302.667 mil habitantes (IBGE, 2018). O clima da região é quente e úmido, com temperatura média anual variando entre 25 e $28{ }^{\circ} \mathrm{C}$, caracterizado por umidade e pluviosidade elevadas com índice pluviométrico anual variando de 2.000 a $2.200 \mathrm{~mm}$, o qual tem maior intensidade no inverno (VALENTE et al., 2011). O relevo de Santarém é composto por uma planície, chamada planície Amazônica, tendo suas rochas da formação Alter-do-Chão (VALENTE et al., 2011).

O município apresenta $43.3 \%$ de domicílios urbanos em vias públicas com arborização (IBGE, 2018). Onde, o bairro Centro foi a área da realização do censo da vegetação 
arbórea urbana do presente estudo, tendo como base o inventário quali-quantitativo da arborização urbana, realizado através do Projeto Floresta Urbana realizado Universidade Federal do Oeste do Pará (UFOPA) com a Secretaria Municipal de Meio Ambiente de Santarém (SEMMA), Instituto de Desenvolvimento Florestal e da Biodiversidade do Estado do Pará (Ideflor-bio) e a Secretaria Municipal de Agricultura e Pesca (Semap).

No inventário foram utilizadas planilhas estruturadas para a realização do inventário de todas as árvores com informações como nome vulgar, fitossanidade (com diferentes graus de severidade do ataque), problemas com a raiz (afloramento e sanidade), manejo (caso as copas estejam em conflito com a fiação, iluminação ou sinalização pública e necessidade de poda de manutenção), altura (foram inventariados somente indivíduos com altura superior a $1 \mathrm{~m}$ ), diâmetro a altura do peito (DAP), sanidade dos fustes e copas (cupins, parasitas e podridão), projeção do fuste e da copa (casa ou rua) e fenologia (estado vegetativo, floração e frutificação). Também foram feitos registros fotográficos de todas as árvores inventariadas. Para identificação das famílias e espécies foi utilizada referências bibliográficas especializadas (LORENZI; SOUZA, 2001; LORENZI, 2002).

Após a coleta de dados, as informações foram tabuladas em planilha do Microsoft Excel, e realizada análise de dados. Para analisar a diversidade florística do bairro foi utilizado o Índice de Diversidade de Shannon-Weiner $\left(\mathrm{H}^{\prime}\right)$ e Índice de Equabilidade de Pielou. De acordo com Romani (2011), esse índice é um dos mais utilizados para medir a diversidade florística em áreas urbanas, pois leva em consideração o número de espécies e a sua equitabilidade, ou seja, a uniformidade de distribuição das espécies.

\section{Resultados e Discussões}

A partir do inventario realizado no Bairro Centro, foram levantados 124 indivíduos, distribuídos em 15 espécies, dentro de 10 famílias botânicas, onde foi constatado que a espécie de maior frequência (37,9\% e 47 indivíduos) foi a Mangifera indica L., seguida pelo Ficus sp. (12,9\% e 16 indivíduos), Licania tomentosa (Benth) e Crescentia cujete L. (11,29\% e 14 indivíduos cada) (Tabela 1). Neste contexto, dados apresentados por Grey e Deneke (1986) e Milano e Dalcin (2000) advertem que em uma arborização urbana o ideal é que nenhuma espécie ultrapasse $15 \%$ do total de indivíduos da população arbórea, pois assim minimiza-se a susceptibilidade do desenvolvimento de pragas e doenças. Logo, ao analisar a Tabela 1, é possível observar que apenas a espécie Mangifera indica L. está acima do porcentual indicado, 
o que é possível concluir que a arborização urbana do bairro centro está com uma boa diversidade de espécies. E, no caso de querer utilizar frutíferas em calçadas, deve-se optar pelo uso de espécies que apresentem frutos pequenos, leves e não carnosos (BIONDI; ALTHAUS, 2005), tornando a mangueira uma espécie não indicada para ser cultivada em áreas urbanas.

Tabela 1 - Família, espécies, fitogeografia, número e frequência dos indivíduos inventariados. Fonte: Própria

\begin{tabular}{|c|c|c|c|c|c|}
\hline Família & Espécie & Nome Comum & $\begin{array}{l}\text { Fitogeograf } \\
\text { ia }\end{array}$ & $\mathbf{N}^{\circ}$ & $\begin{array}{c}\text { Fr } \\
(\%)\end{array}$ \\
\hline Anacardiaceae & Mangifera indica $\mathrm{L}$. & Mangueira & Nativa & 47 & 37,90 \\
\hline Annonaceae & Annona squamosa $\mathrm{L}$. & Ateira & Exótica & 1 & 0,81 \\
\hline Bignoniaceae & Crescentia cujete L. & Cuieira & Nativa & 14 & 11,29 \\
\hline Bignoniaceae & Handroanthus serratifolius (Vahl) & Ipê amarelo & Nativa & 6 & 4,84 \\
\hline $\begin{array}{c}\text { Chrysobalanac } \\
\text { eae }\end{array}$ & Licania tomentosa (Benth) & Oiti & Nativa & 14 & 11,29 \\
\hline Combretaceae & Terminalia catappa $\mathrm{L}$. & Castanhola & Exótica & 2 & 1,61 \\
\hline Fabaceae & Acacia obliquifolia Mart. \& Gal. & $\begin{array}{l}\text { Matafome } \\
\text { espinhenta }\end{array}$ & Nativa & 2 & 1,61 \\
\hline Fabaceae & Andira inermis $\mathrm{W}$. Wright & Sapupira & Nativa & 5 & 4,03 \\
\hline Fabaceae & $\begin{array}{c}\text { Cassia ferruginea (Schrad) Schrad ex } \\
\text { DC }\end{array}$ & Chuva-de-ouro & Exótica & 1 & 0,81 \\
\hline Fabaceae & Ormosia Coccinea Aubl. & Tento vermelho & Nativa & 1 & 0,81 \\
\hline Fabaceae & $\begin{array}{c}\text { Senna siamea (Lam.) H.S. Irwin \& } \\
\text { Barneby }\end{array}$ & Cássia-de-Sião & Exótica & 3 & 2,42 \\
\hline Leguminosae & Diplotropis martiusii Benth & $\begin{array}{l}\text { Sapupira da } \\
\text { várzea }\end{array}$ & Exótica & 3 & 2,42 \\
\hline Meliaceae & Azadirachta indica A. Juss & Nim & Exótica & 2 & 1,61 \\
\hline Moraceae & Ficus spp & Ficus & Exótica & 16 & 12,90 \\
\hline Myrtaceae & Psidium guajava L. & Goiabeira & Nativa & 1 & 0,81 \\
\hline NI & NI & NI & - & 6 & 4,84 \\
\hline \multicolumn{4}{|c|}{ Total } & $\begin{array}{c}12 \\
4\end{array}$ & \\
\hline
\end{tabular}

O índice de diversidade de Shannon-Weiner $\left(\mathrm{H}^{\prime}\right)$ obtido foi de 1,94, superior ao obtido por Dantas et al. (2016) que obteve índice de 0,98 ao analisar a arborização da praça Floriano Peixoto na cidade de Macapá. O valor do Índice de Equabilidade de Pielou é proporcional a diversidade florística da comunidade em estudo, ou seja, todas as espécies são igualmente abundantes quando seu valor é 1 (um). No bairro Centro foi encontrado valor de 0,71, abaixo do valor obtido por Silva et al. (2005) que obteve índice máximo de 0,94 ao fazer levantamento arbóreo das praças do municio de Itapuranga, Goiás, logo, é possível verificar que o a bairro apresenta uma média diversidade e relativamente heterogêneo.

De acordo com Tabela 1 é perceptível a predominância de árvores nativas, correspondendo a $72,5 \%$ da vegetação inventariada, fundamental para promover ao ambiente 
urbano características naturais mais semelhantes ao meio rural e, com isso, atuar como abrigo, alimento e corredor ecológico para a fauna local (PINHEIRO; SOUSA 2017). Contrariando Rangel (2005), que afirmou que de $80 \%$ das ruas das cidades brasileiras eram arborizadas com espécies exóticas sendo, estas, a segunda maior ameaça mundial à biodiversidade, perdendo apenas para a destruição de habitat's por ações antrópicas diretas.

\section{Conclusões}

Com base no inventario realizado, pôde-se concluir que a arborização do bairro centro do municio de Santarém demonstra uma média diversidade de espécies, porém a arborização do bairro é antiga e têm-se a necessidade de substituição de indivíduos; a estratégia a partir deste trabalho será a implantação do plano diretor de arborização do Município.

\section{Referências}

BIONDI, D.; ALTHAUS, M. Árvores de rua de Curitiba: cultivo e manejo. Curitiba: FUPEF, 2005. $177 \mathrm{p}$.

BIONDI, D. Floresta urbana. In: BIONDI, D. Floresta urbana. Curitiba; 2015.

BIONDI, D.; LIMA NETO, E. M. Delineamento de Unidades Amostrais Para o Inventário da Arborização de Ruas em Curitiba, PR. Revista da Sociedade Brasileira de Arborização Urbana, Piracicaba - SP, v. 9, n. 1, p. 21 - 34, 2014.

DANTAS, A. R.; GOMES, E. M. C.; PINHEIRO, A. P. DIAGNÓSTICO FLORÍSTICO DA PRAÇA FLORIANO PEIXOTO NA CIDADE DE MACAPÁ, AMAPÁ. Rev. SBAU., Piracicaba - SP, v.11, n.4, p. 32-46, 2016

GONÇALVES, A. M. Avaliação da arborização urbana do bairro Santa Luzia, Itacoatiara, Amazonas. 2018. 52 f. Trabalho de Conclusão de Curso (Engenharia Florestal) Universidade do Estado do Amazonas, Manaus.

GREY, G. W., DENEKE, F. J. Urban forestry. New York, John Wiley \& Sons, 1986. 279 p.

IBGE. Instituto Brasileiro de Geografia e Estatística. 2010. Rio de Janeiro. Ministério do Planejamento, Orçamento e Gestão. Disponível: https://ww2.ibge.gov.br/home/estatistica/pesquisas/indicadores.php. Acesso em: 28. Agos. 2018.

IBGE. Instituto Brasileiro de Geografia e Estatística. Cidades. Pará. Santarém. Disponível $\mathrm{em}:<$ https://cidades.ibge.gov.br/brasil/pa/santarem/panorama $>$. Acesso em: 28. Agos. 2018.

LOPO, D. PERCEPÇÃO, DIAGNÓSTICO E GESTÃO DA ARBORIZAÇÃO E ÁREAS VERDES NAS CIDADES FRONTEIRIÇAS BRASIL - BOLÍVIA. 2014. 128 f. Dissertação 
(Estudos Fronteiriços) - Fundação Universidade Federal de Mato Grosso do Sul, Campus do Pantanal.

LORENZI, H.; SOUZA, H. M. Plantas ornamentais no Brasil: arbustivas, herbáceas e trepadeiras.3. ed. Nova Odessa: Instituto Plantarum, 2001.

LORENZI, H. Árvores Brasileiras: Manual de Identificação e Cultivo de Plantas Arbóreas do Brasil, v.1, 4.ed. Nova Odessa, SP: Instituto Plantarum, 2002.

MILANO, M.; DALCIN, E. Arborização de vias públicas. Rio de Janeiro: LIGHT, 2000. 226p.

SILVA, A.O.; ALVES, M.L.; MIRANDA, S.C. Levantamento da vegetação arbórea em praças no município de Itapuranga-GO. Revista Magistra, Cruz das Almas, v. 27, n.2, p. 179 - 1887, 2015.

PAULA, L.; DUARTE, M. S. S.; TOSTES, R. B.; OLIVEIRA JUNIOR, P. R.; RUBACK, S. S. Arborização urbana do bairro Centro do município de Cataguases, MG. Revista Agrogeoambiental, Pouso Alegre, v. 7, n. 2, p. 101-112, jun. 2015.

PINHEIRO, C. R.; SOUZA, D. D. A importância da arborização nas cidades e sua influência no microclima. R. gest. sust. Ambiente., Florianópolis, v. 6, n. 1, p.67 - 82, 2017.

RANGEL, S. A arborização urbana e o uso de espécies florestais nativas da mata atlântica. Disponível em $<$ http://www.cpatc.embrapa.br/index.php?idpagina $=$ artigos\&artigo $=360 \&$ showaqui sicao $=$ true > Acesso em: 31 Agos. 2018.

ROMANI, G. N. Análise florística, fitossociológica e qualitativa da arborização nas Praça XV de novembro em Ribeirão Preto, SP. 2011. 78 f. Dissertação (Mestrado) - Universidade Estadual Paulista, Faculdade de Ciências Agrárias e Veterinárias, Jaboticabal, SP.

VALENTE, R. M.; SILVA, J. M. C.; STRAUBE, F. C.; NASCIMENTO, J. L. X. Conservação de aves migratórias neárticas no Brasil. In: Conservação Internacional. 2011. Belém. p. 400. 